\title{
Mediated enzyme screen-printed electrode probes for clinical, environmental and food analysis
}

\author{
Francesco Ricci, Danila Moscone and Giuseppe Palleschi
}

\subsection{INTRODUCTION}

Since the appearance of the first amperometric biosensors based on the coupling of oxidase enzymes and relying on the final detection of $\mathrm{H}_{2} \mathrm{O}_{2}$, it was clear that one of the major problems related to this kind of configuration was due to the high overpotential needed for $\mathrm{H}_{2} \mathrm{O}_{2}$ oxidation (ca. $0.7 \mathrm{~V}$ vs. $\mathrm{Ag} / \mathrm{AgCl}$ ). At this potential in fact, many electroactive substances (i.e. ascorbic acid, uric acid etc.), usually present in real samples, could also be oxidised to give interfering signals.

The same problem was also present when other amperometric biosensors, based on different class of enzymes, were assembled. For example, the amperometric detection of nicotinamide adenine dinucleotide $(\mathrm{NADH})$ has been a matter of investigation for many years in the biosensor field $[1,2]$.

The problem associated with amperometric detection of $\mathrm{NADH}$ is similar to that of $\mathrm{H}_{2} \mathrm{O}_{2}$, with a very high overpotential required $[3,4]$ and with electrode fouling due to the presence of radical intermediates produced during $\mathrm{NADH}$ oxidation that then interfere with the measurement [5].

Another class of enzymes that has found wide application in the biosensor field in the last decades is that of the cholinesterases which have been mainly used for the detection of pesticides. For the amperometric detection of cholinesterase activity, both the substrates acetylcholine and acetylthiocholine have been extensively used [6-9], the latter being preferred because this avoids the use of another enzyme, choline oxidase, which is usually coupled with acetylcholinesterase. However, the amperometric measurement of thiocholine, produced by 
the enzymatically catalysed hydrolysis of acetylthiocholine, is difficult to achieve at classic electrode surfaces due to the high overpotential needed and possible problems of surface passivation [9-11].

For these reasons, the drawbacks of electrochemical interferences are the primary subject of many research groups involved in the biosensor field, and strategies to overcome them have become a major goal.

First approaches to solving this problem were based on the use of selective membranes [12], which however still pose some problems of response time, of time-consuming procedures during the assembling, decrease in sensor sensitivity and detection limit. Research activity was then devoted to obtaining a sensor capable of detecting the analyte $\left(\mathrm{H}_{2} \mathrm{O}_{2}, \mathrm{NADH}\right.$, thiols etc. $)$ in a potential range where electrochemical interferences could be avoided or greatly minimised. It is well known that this potential range, which could be defined as "optimum", is usually located between 0.0 and $-0.2 \mathrm{~V}$ vs. $\mathrm{Ag} / \mathrm{AgCl}$ [13].

To work in this optimum range, different kinds of approaches were proposed depending on the analyte and on the electrode surface.

First examples of the amperometric detection of $\mathrm{H}_{2} \mathrm{O}_{2}$ accomplished in such a range were based on the use of an enzyme, namely horseradish peroxidase (HRP), a prototypical hemeprotein peroxidase, which catalyses the reduction of $\mathrm{H}_{2} \mathrm{O}_{2}$ and due to its peculiar structure, allows direct electron transfer between its active site and the electrode surface at low applied potential [14-17]. This approach, although it shows good sensitivity and accuracy, suffers from some important shortcomings such as low stability and the limited binding of HRP to solid surfaces.

For this reason, in the last decade, inorganic electrochemical mediators, which catalyse the oxidation or reduction of $\mathrm{H}_{2} \mathrm{O}_{2}$ have been preferred to HRP and have been used for the assembling of oxidasebased biosensors [18-20]. This results in a decrease of the applied potential and the consequent avoidance of electrochemical interferences. Many electrochemical mediators have been used and many of them have found broad application, especially in glucose biosensors for diabetes control. However, due to the solubility of the mediator, they are generally employed in a single-use sensor and present some problems due to the low operative stability.

\subsubsection{Prussian blue as electrochemical mediator}

In this perspective, hexacyanoferrates and in particular Prussian blue (ferric hexacyanoferrate-PB) have found a wide use [21-23]. It was in 
1994 that Karyakin made the claim for a PB-modified electrode as a powerful tool for hydrogen peroxide detection at low applied potential [24]. He demonstrated the possibility of the effective electrochemical deposition of a PB layer onto a glassy carbon electrode providing an efficient and selective catalytic activity towards hydrogen peroxide reduction $[24,25]$. PB-modified glassy carbon electrodes were used at an applied potential of $0.0 \mathrm{~V}$ vs. $\mathrm{Ag} / \mathrm{AgCl}$ with a sensitivity in the micromolar range [26] and they showed, under the optimised conditions (thin layer of $\mathrm{PB}$ ), a bimolecular rate constant for the reduction of $\mathrm{H}_{2} \mathrm{O}_{2}$ of $3 \times 10^{3} \mathrm{~mol}^{-1} \mathrm{ls}^{-1}$, which is very similar to that measured for the peroxidase enzyme $\left(2 \times 10^{4} \mathrm{~mol}^{-1} \mathrm{ls}^{-1}\right)$ [27]. This high catalytic activity and selectivity led Karyakin to consider PB as an "artificial peroxidase". The operating potential (i.e. $0.0 \mathrm{~V}$ vs. $\mathrm{Ag} / \mathrm{AgCl}$ ) was low enough to avoid, or greatly reduce, the contribution from all the most common interferents (ascorbic acid, paracetamol, uric acid) [25,26], rendering the PB-modified electrode selective for hydrogen peroxide. However, the low applied potential does not by itself explain the high selectivity of $\mathrm{PB}$. This feature has been accounted for in terms of the structure of $\mathrm{PB}$ which enables low molecular weight molecules to penetrate the cubic lattice and to be reduced while excluding molecules with higher molecular weight. This is probably the main advantage of using $\mathrm{PB}$ as mediator for $\mathrm{H}_{2} \mathrm{O}_{2}$ reduction. The selectivity and activity achieved are comparable to that of a biological binding component (HRP) but with all the advantages of an inorganic species (low cost, high stability at certain conditions, ease of electrode surface modification and no saturation effect for substrate) [21]. For this reason, much attention has been devoted to PB-modified electrodes; and their use has increased in recent years. PB-modified glassy carbon [26,28,29], graphite [30-32], carbon paste [33] and platinum [34] electrodes have been studied, leading to the construction of biosensors for glucose [25,35], lactate [36], glutamate [37], aminoacid [30] and alcohol [26] detection. Recently, some reviews on the analytical applications of PB have appeared in the literature [21-23,38]. Among the classic electrode materials, the screen-printing (thick-film) technology applied to sensor and biosensor construction has been considerably improved during recent years and a large number of papers, and recently some reviews, have been published on this subject [39-41]. Screen-printed electrodes (SPEs) are in fact inexpensive, simple to prepare, rapid and versatile and this technology also appears to be the most economical means for large-scale production and for the assembling of spot tests for clinical and environmental analysis. The use of screen-printed electrodes 
coupled with a redox mediator is dependent on the procedure adopted for its deposition on the electrode surface. This was initially one of the drawbacks for the coupling of the screen-printing technology and PB. Almost all the procedures adopted for PB deposition are in fact based on an electrochemical step which employs a constant applied potential (galvanostatic) in a solution of ferricyanide and ferric chloride $[26,29,35,37,42,43]$ or potential cycling in the same solutions [42]. The galvanostatic strategy is usually followed by (1) a series of cyclic voltammetry $(\mathrm{CV})(15-25)$ which enables a sort of activation of the $\mathrm{PB}$ layer and (2) by a heating step $\left(100^{\circ} \mathrm{C}\right.$ for $\left.1-1.5 \mathrm{~h}\right)$ for the stabilisation of the same layer. All these procedures, however, present two major drawbacks. The first one is related to the fact that any procedure for surface modification which involves the use of an electrochemical step is always difficult to adapt to a large-scale production of sensors. All the electrochemical procedures adopted for PB modification are thus not suitable for the modification of a large number of screen-printed electrodes in a limited time. Another reason which makes the electrochemical procedure less than optimal for $\mathrm{PB}$ deposition is the low operative stability at alkaline $\mathrm{pH}$ of the $\mathrm{PB}$ layer formed $[33,42,44]$. This fact limited the choice of the oxidase enzymes that could be coupled with PB-modified electrodes to those having a $\mathrm{pH}$ optimum in the acid range. The reason for this limited stability is probably to be ascribed to the strong interaction between ferric ions and hydroxyl ions $\left(\mathrm{OH}^{-}\right)$which form $\mathrm{Fe}(\mathrm{OH})_{3}$ at $\mathrm{pH}$ higher than 6.4 [45] thus leading to the destruction of the $\mathrm{Fe}-\mathrm{CN}-\mathrm{Fe}$ bond, and hence solubilising $\mathrm{PB}$ [46]. Its leakage from the electrode surface results in a decreased signal. For many years, this low stability has represented the main drawback to the use of PB-modified electrodes, especially when they are coupled with an enzyme having its optimum $\mathrm{pH}$ in the basic range $[42,47]$.

Our research in this field, which is summarised in this chapter, has been directed at obtaining a sensor modified with PB as electrochemical mediator which could avoid electrochemical interferences and could also couple the advantages of the screen-printed electrodes. For this purpose, an in-depth study of the modification procedure for PB deposition on the electrode surface was first conducted and then when an optimised procedure capable of providing an efficient and stable PB layer was obtained, it was applied with screen-printed electrodes in real analytical systems. Thus, our main goal has been not only to obtain a PB modification procedure suitable for a mass production of modified screen-printed electrodes, as already pointed out above, but also to achieve a stable PB layer in terms of operative and storage stability. 
Moreover, the use of $\mathrm{PB}$ will not only be limited to the detection of $\mathrm{H}_{2} \mathrm{O}_{2}$ and its use in conjunction with oxidase enzymes. A recent disclosure of the electrocatalytic activity of $\mathrm{PB}$ towards the oxidation of thiols will also be discussed and an application with acetylcholinesterase enzymes for pesticide detection reported.

\subsection{APPLICATION}

Screen-printed electrodes used for the PB modification were home produced. A detailed description of the electrodes used and of the procedure adopted for PB modification is found in Procedure 17 (in CD accompanying this book). The most important thing to note about this procedure is that it does not involve any electrochemical step and, for this reason, it has been designed as "chemical deposition". This procedure is also very easy to perform and could be adapted to mass production of modified electrodes (see Procedure 17 in CD accompanying this book). The suitability of the proposed deposition procedure was carefully evaluated with different electrochemical techniques and its application in real samples has been summarised and discussed here.

\subsubsection{Prussian blue modified screen-printed electrodes as sensitive and stable probes for $\mathrm{H}_{2} \mathrm{O}_{2}$ and thiol measurements}

PB-modified electrodes have been first tested as $\mathrm{H}_{2} \mathrm{O}_{2}$ probes for which the response time, detection limit, linear range, sensitivity and reproducibility were studied.

The analytical parameters with respect to $\mathrm{H}_{2} \mathrm{O}_{2}$ amperometric measurement were evaluated in both batch and continuous flow mode and their stability, especially at basic $\mathrm{pHs}$, was studied.

All these results were obtained using screen-printed electrodes with batch amperometric or continuous flow techniques (for more details see Procedure 17 in CD accompanying this book).

The catalytic activity of $\mathrm{PB}$ towards $\mathrm{H}_{2} \mathrm{O}_{2}$ and thiocholine is demonstrated by CV experiments and summarised in Fig. 24.1, which shows the behaviour of the $\mathrm{PB}$ oxidation and reduction peaks in response to the injection of different concentrations of $\mathrm{H}_{2} \mathrm{O}_{2}$ and thiocholine in a buffer solution. In the presence of $\mathrm{H}_{2} \mathrm{O}_{2}$, the increase of the reduction peak together with the decrease of the oxidation peak clearly indicates the activity of the reduced form of $\mathrm{PB}$ towards the reduction of $\mathrm{H}_{2} \mathrm{O}_{2}$. 

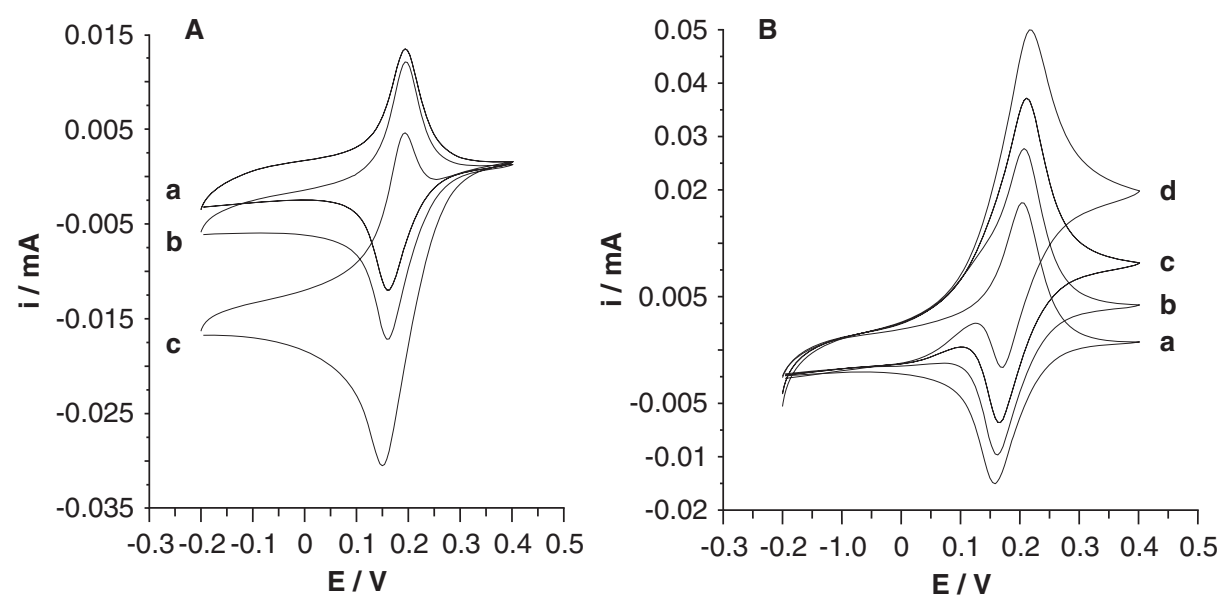

Fig. 24.1. Cyclic voltammograms revealing the catalytic oxidation of $\mathrm{H}_{2} \mathrm{O}_{2}$ (A) and thiocholine (B) at a PB-modified SPE. (A) CVs obtained in the absence (a) and presence of 0.5 (b) and $2.0 \mathrm{mmoll}^{-1}$ (c) of $\mathrm{H}_{2} \mathrm{O}_{2}$. (B) CVs obtained in the absence (line a) and presence of 3 (line b), 6 (line c) and $15 \mathrm{mmoll}^{-1}$ (line d) of thiocholine. Scan rate: $10 \mathrm{mV} \mathrm{s}^{-1} .0 .05 \mathrm{moll}^{-1}$ phosphate buffer $+0.1 \mathrm{moll}^{-1}$ $\mathrm{KCl}, \mathrm{pH} 7.4$.

In the case of thiocholine, on the other hand, the oxidation peak is increased while the reduction one is diminished. This demonstrates that $\mathrm{PB}$ acts as electrocatalyst for the oxidation of thiocholine, decreasing its overpotential.

\subsubsection{1 $\mathrm{H}_{2} \mathrm{O}_{2}$ measurement in batch amperometry}

PB-modified screen-printed electrodes were first tested in batch amperometry for $\mathrm{H}_{2} \mathrm{O}_{2}$ detection. The sensors showed a good linearity in the range between 0.1 and $100 \mu \mathrm{moll}^{-1}$ with a detection limit of $0.1 \mu \mathrm{mol} \mathrm{l}^{-1}$. The regression equation of the linear part of the curve was $y=22.90 x-0.013$, where y represents the current in $\mu \mathrm{A}$ and $\mathrm{x}$ the $\mathrm{H}_{2} \mathrm{O}_{2}$ concentration in $\mathrm{mmoll}^{-1}$; the $R^{2}$ value was 0.9980 . The sensitivity was $324 \mu \mathrm{A} \mathrm{mmoll}{ }^{-1} \mathrm{~cm}^{-2}$ with an RSD\% of $5 \%$ (for all the concentrations tested by six different electrodes) (see Table 24.1).

The interference signal due to the most common electrochemical interfering species was also evaluated by the comparison of the signal for a fixed concentration of $\mathrm{H}_{2} \mathrm{O}_{2}$ with the current value obtained in the presence of the same concentration $\left(0.05 \mathrm{mmol}^{-1}\right)$ of the interfering species. The relative current signal gives a measure of the sensor selectivity. Results showed a high selectivity of the $\mathrm{H}_{2} \mathrm{O}_{2}$ sensor. The 
TABLE 24.1

Analytical parameters of PB-modified SPEs for $\mathrm{H}_{2} \mathrm{O}_{2}$ and thiocholine

\begin{tabular}{|c|c|c|c|c|c|c|c|c|c|}
\hline Analyte & $\begin{array}{l}\text { Applied } \\
\text { potential (mV } \\
\text { vs. } \mathrm{Ag} / \mathrm{AgCl})\end{array}$ & $\begin{array}{l}\text { Amperometric } \\
\text { method }\end{array}$ & $\begin{array}{l}\text { Detection } \\
\text { limit } \\
\left(\mu \mathrm{moll}^{-1}\right)\end{array}$ & $\begin{array}{l}\text { Noise } \\
\left(\mathrm{nAcm}^{-2}\right)\end{array}$ & $\begin{array}{l}\text { Linearity range } \\
\left(\mathrm{moll}^{-1}\right)\end{array}$ & $\begin{array}{l}\text { Sensitivity } \\
\left(\mathrm{mA} \mathrm{mol}^{-1} \mathrm{lcm}^{-2}\right)\end{array}$ & $\begin{array}{l}\operatorname{RSD} \% \\
(n=5)\end{array}$ & $\begin{array}{l}\text { Time to reach } \\
\text { stable } \\
\text { background(s) }\end{array}$ & $\begin{array}{l}\text { Time to reach } \\
90 \% \text { of the } \\
\text { signal (s) }\end{array}$ \\
\hline $\mathrm{H}_{2} \mathrm{O}_{2}$ & -50 & $\begin{array}{l}\text { Batch } \\
\text { amperometry }\end{array}$ & 0.1 & 2 & $0.1 \times 10^{-6}-0.05 \times 10^{-3}$ & 324 & 5 & 60 & 5 \\
\hline $\mathrm{H}_{2} \mathrm{O}_{2}$ & -50 & $\begin{array}{l}\text { Continuous } \\
\text { flow } \\
\left(10 \mu \mathrm{l} \mathrm{min}^{-1}\right)\end{array}$ & 1.0 & 20 & $1.0 \times 10^{-6}-1.0 \times 10^{-3}$ & 213 & 5 & 120 & 30 \\
\hline Thiocholine & +200 & $\begin{array}{l}\text { Batch } \\
\text { amperometry }\end{array}$ & 5.0 & 57 & $5.0 \times 10^{-6}-0.5 \times 10^{-3}$ & 143 & 7 & 60 & 5 \\
\hline
\end{tabular}


interference due to ascorbic acid is around $2 \%$, while there was no signal due to uric acid and catechol.

\subsubsection{2 $\mathrm{H}_{2} \mathrm{O}_{2}$ measurement in continuous flow mode}

The magnitude of the hydrogen peroxide signal and electrochemical interferences as well as operational and storage stability were also evaluated in a continuous flow mode. These results were utilised to determine whether these sensors could be used in flow mode for continuous glucose monitoring after coupling the sensor with glucose oxidase.

The detection limit for $\mathrm{H}_{2} \mathrm{O}_{2}(\mathrm{~s} / \mathrm{n}=3)$ obtained was $10^{-6} \mathrm{moll}^{-1}$ while the linear range was between $10^{-6}$ and $10^{-3} \mathrm{moll}^{-1}$, the noise current in the range 15-20 nA and the sensitivity towards hydrogen peroxide was $213 \mathrm{~mA} \mathrm{~mol}^{-1} \mathrm{l}^{-1} \mathrm{~cm}^{2}$. The time needed to reach a stable current background was around $2 \mathrm{~min}$, while $30 \mathrm{~s}$ were sufficient to reach $90 \%$ of the final signal after the injection of the hydrogen peroxide (i.e. $10^{-4} \mathrm{moll}^{-1}$ ). Reproducibility of these sensors was $5 \%$ $(n=5)$.

The effect of the substances that usually interfere in the electrochemical determination of glucose was also examined with this technique. The signal due to ascorbic acid, uric acid, 4-acetaminophenol was evaluated using a fixed concentration of $0.5 \mathrm{mmoll}^{-1}$. No response was observed for these electrochemical interferents except for ascorbic acid, which gave a signal equal to $3 \%$ of the hydrogen peroxide. These results demonstrated that neither the sensitivity nor the selectivity of the PB-modified sensors changed when using different amperometric techniques.

\subsubsection{Stability of Prussian blue modified screen-printed electrodes}

The operational stability of all the PB-modified sensors is a critical point, especially at neutral and alkaline $\mathrm{pH}$. A possible explanation for reduced stability could be the presence of hydroxyl ions at the electrode surface as a product of the $\mathrm{H}_{2} \mathrm{O}_{2}$ reduction. Hydroxyl ions are known to be able to break the Fe-CN-Fe bond, hence solubilising the PB [21]. An increased stability of $\mathrm{PB}$ at alkaline $\mathrm{pH}$ was first observed by our group after adopting a chemical deposition method for the modification of graphite particles with $\mathrm{PB}$ for the assembling of carbon paste electrodes [48].

A similar stability was obtained with our PB-modified screen-printed electrodes. The operational stability was studied using both CV and amperometry. In the first case, the sensors were cycled 250 times at 
different $\mathrm{pHs}$ and the decrease of the oxidation and reduction peaks was measured as a function of time.

The modified electrode showed a very good stability even at pH 9 . Although at this $\mathrm{pH}$ a decrease in the redox peaks in $\mathrm{CV}$ is observed after 250 cycles, the PB layer is still highly electroactive and sufficient to catalyse the $\mathrm{H}_{2} \mathrm{O}_{2}$ reduction. In fact, stirred batch amperometric measurements of $\mathrm{H}_{2} \mathrm{O}_{2}\left(10 \mu \mathrm{moll}^{-1}\right)$ were carried out before and after the continuous cycling at $\mathrm{pH} 9$, and the decrease of the signal was only $10 \%$ of the initial value.

When tested in stirred batch amperometry, the PB-modified screenprinted electrodes showed no loss of signal for $\mathrm{H}_{2} \mathrm{O}_{2}\left(20 \mu \mathrm{moll}^{-1}\right)$ after $50 \mathrm{~h}$ at $\mathrm{pH} 7.4$ in batch amperometry. Other experiments performed at $\mathrm{pH} 9$ confirmed the high $\mathrm{pH}$ stability of the PB-modified SPEs produced. At $\mathrm{pH} 9$ there was still $80 \%$ of the residual activity of $\mathrm{PB}$ recorded after $16 \mathrm{~h}$ of continuous work in a solution of $\mathrm{H}_{2} \mathrm{O}_{2}$ $\left(20 \mathrm{mmoll}^{-1}\right)$ (Table 24.2).

In continuous flow mode, the stability experiments were carried out for a total period of 48 and $100 \mathrm{~h}$. Two different solutions $(0.1$ and $0.2 \mathrm{mmoll}^{-1}$ ) of hydrogen peroxide were continuously passed in the wall-jet cell and the signal was first recorded for a total of $48 \mathrm{~h}$. A decrease of around $10 \%$ and $15 \%$, respectively, was detected at the end of $48 \mathrm{~h}$ of monitoring for 0.1 and $0.2 \mathrm{mM}$. Under these conditions (presence of hydrogen peroxide and an applied potential), PB is forced to continuously change its oxidative state according to the following equation (Eq. (24.1)) [28]:

$$
\left(\mathrm{PB}_{\mathrm{red}}\right) \mathrm{K}_{4} \mathrm{Fe}_{4}^{2+}\left[\mathrm{Fe}^{2+}(\mathrm{CN})_{6}\right]_{3} \rightleftarrows\left(\mathrm{PB}_{\mathrm{ox}}\right) \mathrm{Fe}_{4}^{3+}\left[\mathrm{Fe}^{2+}(\mathrm{CN})_{6}\right]_{3}+4 \mathrm{~K}^{+}+4 \mathrm{e}^{-}
$$

From the results obtained in this study, it seems that the crucial point concerning the stability of the $\mathrm{PB}$ is represented by this reaction. When conditions are such that the $\mathrm{PB}$ is not forced to go into the oxidised form (less stable), the stability of the PB layer is very high. This is probably the reason why, in the absence of an applied potential and of hydrogen peroxide, the PB retained $100 \%$ of its activity even after $100 \mathrm{~h}$ of continuous flow of buffer (data not shown), while in the case of the applied potential and in the presence of hydrogen peroxide a decrease was observed. Moreover, it should be pointed out that even taking into consideration the slight decrease, the stability of the PB layer is extremely good and this is quite new for PB-based sensors, which have always been affected by a low stability [25]. 
TABLE 24.2

Operational amperometric $\mathrm{pH}$ stability: \% of residual activity of PB-modified screen-printed electrode in continuous flow mode at different conditions

\begin{tabular}{|c|c|c|c|c|c|c|}
\hline Analyte & $\begin{array}{l}\text { Applied } \\
\text { potential }(\mathrm{mV} \\
\text { vs. } \mathrm{Ag} / \mathrm{AgCl})\end{array}$ & Amperometric method & $\begin{array}{l}\text { Time of } \\
\text { operation }\end{array}$ & $\mathrm{pH}$ & {$\left[\mathrm{H}_{2} \mathrm{O}_{2}\right]$} & $\begin{array}{l}\text { Residual } \\
\text { activity }\end{array}$ \\
\hline $\mathrm{H}_{2} \mathrm{O}_{2}$ & -50 & Batch amperometry & $50 \mathrm{~h}$ & 7.4 & $20 \mu \mathrm{moll}^{-1}$ & 100 \\
\hline $\mathrm{H}_{2} \mathrm{O}_{2}$ & -50 & $\begin{array}{l}\text { Continuous flow } \\
\text { amperometry } \\
\left(10 \mu \mathrm{lmin}^{-1}\right)\end{array}$ & $48 \mathrm{~h}$ & 7.4 & $0.1 \mathrm{mmoll}^{-1}$ & 90 \\
\hline $\mathrm{H}_{2} \mathrm{O}_{2}$ & -50 & $\begin{array}{l}\text { Continuous flow } \\
\text { amperometry } \\
\left(10 \mu \mathrm{lmin}^{-1}\right)\end{array}$ & $100 \mathrm{~h}$ & 7.4 & $0.2 \mathrm{mmol} \mathrm{l}^{-1}$ & 90 \\
\hline $\mathrm{H}_{2} \mathrm{O}_{2}$ & -50 & $\begin{array}{l}\text { Cyclic } \\
\text { voltammetry+batch } \\
\text { amperometry }\end{array}$ & 250 cycles & 9.0 & $10 \mu \mathrm{mol} l^{-1}$ & 90 \\
\hline $\mathrm{H}_{2} \mathrm{O}_{2}$ & -50 & Batch amperometry & $16 \mathrm{~h}$ & 9.0 & $20 \mu \mathrm{moll}^{-1}$ & 80 \\
\hline
\end{tabular}

All the values are the average of three electrodes. 
As already pointed out in our previous papers [48-50], the high stability is probably the result of the newly developed chemical modification procedure which may lead to a stronger adsorption of the PB particles on the electrode surface. In contrast to the PB layer obtained with the more commonly used electrochemical procedures, these modified electrodes are in fact more stable at basic $\mathrm{pH}$ and their continuous use is possible with a minimal loss of activity after several hours. Moreover, with respect to the electrochemical procedure, our chemical deposition is much more suitable for mass production since no electrochemical steps are required and a highly automated process could be adopted (see Procedure 17 in CD accompanying this book).

A test of the operational stability has also been carried out using electrodes after storage at room temperature for 6 months. The electrodes showed the same behaviour during $100 \mathrm{~h}$ of monitoring. As shown in Fig. 24.2, the stability was very good with a loss of ca. 15\% observed after $100 \mathrm{~h}$. This demonstrates that the stability of the PB layer does not decrease even after a long period of storage.

Finally, the PB electrodes have been tested in terms of their storage stability. To do this, the electrodes were left dry at room temperature in the dark after the surface modification. One year after their production, the $\mathrm{PB}$ electrodes tested for $\mathrm{H}_{2} \mathrm{O}_{2}$ reduction, retained $90 \pm 10 \%(n=10)$ of their initial signal response to hydrogen peroxide.

\subsubsection{Thiol measurements with PB-modified screen-printed electrodes}

Our group has recently investigated the possibility of using $\mathrm{PB}$ as catalyst also for the oxidation of thiols and, for the first time to our knowledge, an extensive study of the electrocatalytic response of PB-modified SPEs to many thiol compounds was performed to better understand the parameters affecting the catalytic mechanism [9].

Thiocholine was studied first as a standard thiol compound because of its importance in environmental analysis. Determination of thiocholine is in fact usually carried out to evaluate the degree of inhibition of acetylcholinesterase, a target enzyme of pesticides, as a means for indirect measurements of organophosphorous and carbamate pesticides.

The effect of PB modification on thiocholine oxidation at the SPE surface has already been demonstrated with voltammetric experiments (Fig. 24.1) [9]. In the case of CVs recorded with PB-modified electrodes in the presence of thiocholine, the current due to $\mathrm{PB}$ oxidation starts to increase (with respect to that obtained in buffer solution) at ca. $100 \mathrm{mV}$ 
F. Ricci, D. Moscone and G. Palleschi
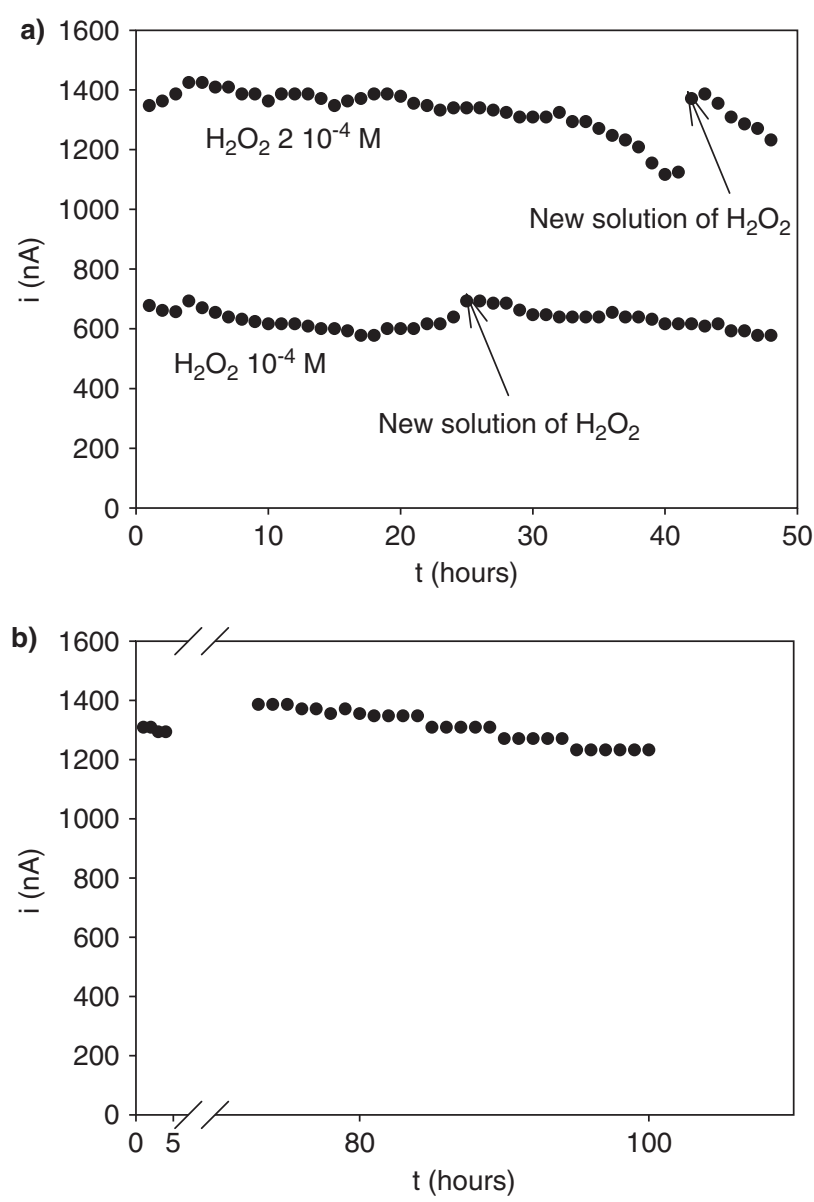

Fig. 24.2. Operational stability of hydrogen peroxide sensors (PB-modified sensors). Applied potential $-50 \mathrm{mV}$ vs. int. ref. Continuous monitoring of current in continuous flow mode $\left(10 \mu \mathrm{lmin}^{-1}\right)$. Arrows indicate where solution of hydrogen peroxide was renewed. (a) Two sensors tested with $10^{-4}$ and $2 \times 10^{-4} \mathrm{moll}^{-1}$ of hydrogen peroxide. (b) Six months old sensor tested with a solution of $2 \times 10^{-4} \mathrm{moll}^{-1}$ of hydrogen peroxide. Reprinted from Ref. [59] with permission from Elsevier.

vs. $\mathrm{Ag} / \mathrm{AgCl}$ while, in the reverse scan, a decrease of the reduction current is observed. The oxidation current observed in the presence of thiocholine seems, in fact, to appear in correspondence with the formation of the oxidised form of $\mathrm{PB}\left(\mathrm{Fe}^{\mathrm{III}} \mathrm{Fe}^{\mathrm{II}}(\mathrm{CN})_{6}\right)$. This result seems to demonstrate that $\mathrm{PB}$ has an electrocatalytic activity towards the oxidation of thiocholine. The generic reactions that occur on the 
electrode surface could be postulated as follows:

$$
\begin{aligned}
& \mathrm{PB}_{\text {ox }}+\mathrm{RSH} \rightleftarrows \mathrm{PB}_{\text {red }}+\mathrm{RSSR} \\
& \mathrm{PB}_{\text {red }}+\text { electrode } \rightleftarrows \mathrm{PB}_{\text {ox }}+\text { electrode }
\end{aligned}
$$

According to Eq. (24.2), the injection of RSH causes an increase in the concentration of the $\mathrm{PB}_{\text {red }}$ in the proximity of the electrode, resulting in an increase of the anodic peak current. By contrast, the cathodic peak is proportional to the $\mathrm{PB}_{\mathrm{ox}}$ concentration that is diminished at the electrode surface by the reaction with thiol (RSH). On the basis of CV experiments and after performing a hydrodynamic voltammogram, a potential of $200 \mathrm{mV}$ to be applied at the PB-modified sensor for thiocholine detection was chosen.

A detection limit $(\mathrm{s} / \mathrm{n}=3)$ of $5 \times 10^{-6} \mathrm{moll}^{-1}$ together with a linear range up to $5 \times 10^{-4} \mathrm{moll}^{-1}$ has been reached with a batch amperometric system using thiocholine standard solutions. Reproducibility has been evaluated studying the response to $10^{-4} \mathrm{moll}^{-1}$ of thiocholine for five different sensors giving similar results to those obtained with $\mathrm{H}_{2} \mathrm{O}_{2}$. Other analytical parameters are summarised in Table 24.1 and demonstrate the suitability of PB-modified sensors for thiocholine measurement.

\subsubsection{Biosensor applications of PB-modified screen-printed electrodes}

After demonstrating that the $\mathrm{PB}$ sensors were highly electroactive and sensitive towards both $\mathrm{H}_{2} \mathrm{O}_{2}$ and thiocholine, their coupling with enzymes was studied in order to assemble electrochemical biosensors to be applied in real samples. In this perspective, two applications will be discussed here and are illustrated in Scheme 1. The first one is directed towards glucose detection and is based on the final measurement of $\mathrm{H}_{2} \mathrm{O}_{2}$. The enzyme used is glucose oxidase and the biosensor is intended to be used for the continuous monitoring of glucose in diabetic patients. In the second application, the response due to thiocholine at the PB-modified electrode is used to assemble a pesticide sensor for organophosphorous and carbamate pesticides.

\subsubsection{Glucose biosensors}

In recent years, the use of a microdialysis probe coupled on-line with a glucose biosensor has provided very good results for the continuous monitoring of glucose in diabetic patients [51-54]. 
F. Ricci, D. Moscone and G. Palleschi

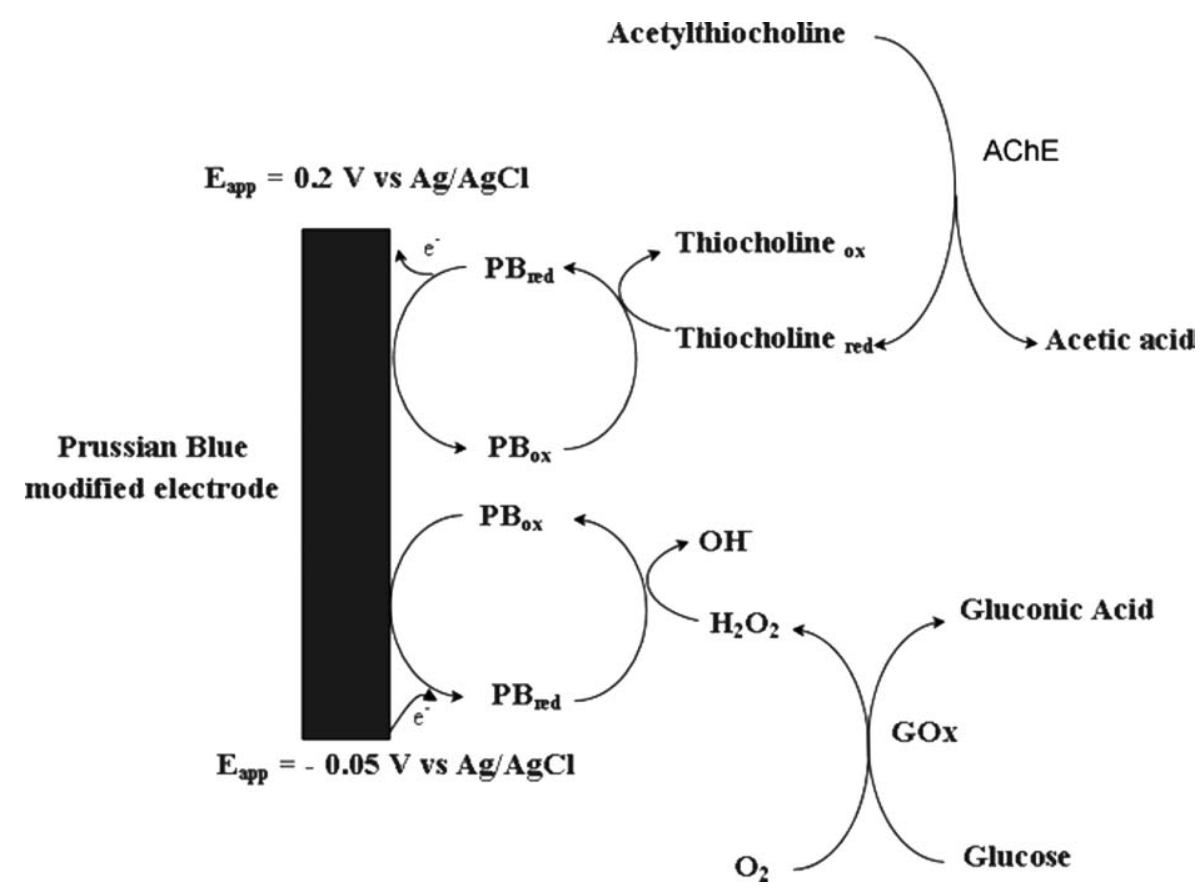

Scheme 1. Schematic representation of the system adopted for glucose and pesticide detection. In the upper part of the scheme is shown the reaction chain for the detection of acetylthiocholine giving a measure of acetylcholinesterase (AChE) activity which can be related to pesticide content. In the lower part of the scheme is shown the classic reaction utilised in the case of an oxidase enzyme (glucose oxidase-GOx) for the detection of glucose. In the first case, the final product is thiocholine and in the second, $\mathrm{H}_{2} \mathrm{O}_{2}$, both are measured at the Prussian blue modified electrode at an applied potential of $0.2 \mathrm{~V}$ vs. $\mathrm{Ag} / \mathrm{AgCl}$ and $-0.05 \mathrm{~V}$ vs. $\mathrm{Ag} / \mathrm{AgCl}$, respectively.

We report here the results obtained by the use of a screen-printed electrode as electrochemical probe to be coupled with a microdialysis fibre for continuous glucose monitoring. The most significant advance is represented by the introduction of a mediator (PB) as the principal factor for hydrogen peroxide measurement. The improved operational stability observed with the PB-modified screen-printed electrodes has demonstrated that these sensors could serve as tool to be applied for the continuous monitoring of many analytes. The application to diabetic care seems to be the most promising and advantageous area in which to test these sensors.

PB-modified electrodes were used as support for glucose oxidase immobilisation (see Procedure 17 in CD accompanying this book for 
details) to assemble biosensors that could be used for the continuous monitoring of glucose. The performance of the glucose biosensors was first tested in terms of the glucose signal and the most important analytical parameters were evaluated. A detection limit of around $2 \times 10^{-5} \mathrm{moll}^{-1}$ was obtained together with a linear range up to $1 \mathrm{mmol}^{-1}$. The reproducibility of these biosensors was $7 \%(n=5)$. The sensitivity of the biosensors was $54 \mathrm{~mA} \mathrm{~mol}^{-1} \mathrm{l}^{-1} \mathrm{~cm}^{2}$ and the current noise signal was almost the same as that obtained with the PB-modified electrodes (15-20 nA). The sensitivity of the biosensors towards glucose was almost $25 \%$ with respect to that obtained for hydrogen peroxide. This result is probably related to the composition of the enzymatic membrane. The presence of Nafion, a polyanionic membrane, could in fact have a shielding effect which results in the lower signal of glucose relative to that of hydrogen peroxide.

A very important parameter for a system designed to be used for continuous monitoring of glucose is the response time, which should be as short as possible in order to detect any changes of the analyte concentration in real time. The response time is dependent on the geometry and internal volume of the cell and on the flow rate $\left(10 \mu \mathrm{min}^{-1}\right)$. To reach $90 \%$ of the final signal for glucose $\left(0.5 \mathrm{mmoll}^{-1}\right)$ starting from the background signal (buffer solution), 2 min were required. Another important characteristic to be taken into account is the time needed to reach the stable baseline. In this case, a time of 3-5 min is necessary to reach a stable current with buffer solution.

\subsubsection{Operational stability of the glucose biosensors}

Glucose biosensors were then tested in terms of operational stability. In this case, they were inserted into a wall-jet cell and when the baseline due to the buffer solution was reached, the glucose solution $\left(0.5 \mathrm{mmoll}^{-1}\right)$ was passed into the cell. The signal due to glucose was recorded continuously for 50 and out to $72 \mathrm{~h}$. Results are reported in Fig. 24.3. From these data, it could be concluded that the enzyme immobilisation procedure adopted provides a high operational stability under these operative conditions. The decrease of the signal is more pronounced during the first $12 \mathrm{~h}$ where an average loss of the signal of $20 \%$ is observed. After this initial period, the signal from the control solution of glucose was highly stabilised and a further decrease of $10-15 \%$ was observed during the next $40-50$ h. In Fig. 24.3 the continuous monitoring (one point every $3 \mathrm{~min}$ ) of some of the tested electrodes is shown. As already pointed out, the stability is very high and all the electrodes showed a similar trend. By comparing these results with 
F. Ricci, D. Moscone and G. Palleschi

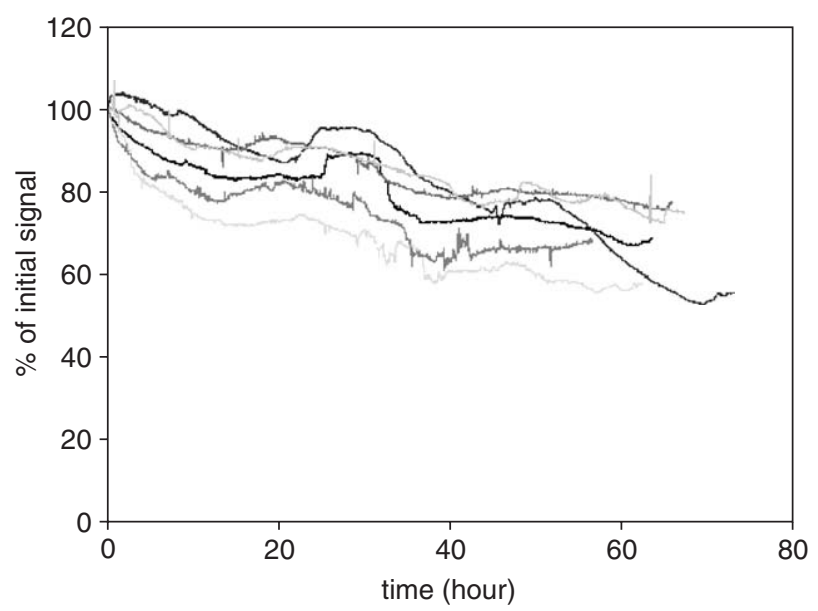

Fig. 24.3. Operative stability of six different glucose biosensors from a minimum of 50 and a maximum of $72 \mathrm{~h}$. Continuous flow mode: $10 \mu \mathrm{lmin}{ }^{-1}$. Glucose concentration: $0.5 \mathrm{mmoll}^{-1}$. Applied potential: $-50 \mathrm{mV}$ vs. int. ref. The current was continuously recorded for the whole experiment. Reprinted from Ref. [59] with permission from Elsevier.

those obtained with PB-modified electrodes it is possible to say that the decrease of the signal can be almost completely ascribed to enzyme inactivation. The initial drift of the signal in the first $12 \mathrm{~h}$ is also probably due to the loss of part of the enzyme which is not strongly bound to the membrane.

Results of the operational stability are extremely interesting for the future application of these probes to continuous monitoring of glucose using a microdialysis probe.

A characteristic that should presently be improved is the limited linear range of the biosensors which could cause some problem in the cases of hyperglycemic levels. Studies are in progress to solve this problem by finding a suitable microdialysis probe which would be able to recover the subcutaneous glucose in the desired range of concentrations.

It should also be pointed out that in the case of an in vivo measurement, the microdialysis probe will be able to recover not only glucose but also many other biological compounds with low molecular weight from the subcutaneous tissue. The electrochemical interferents are greatly reduced by the use of $\mathrm{PB}$ at a low applied potential. However, other biological compounds could negatively affect the stability of the enzymatic membrane. Also, it is possible to have a sort of passivation or fouling of the electrode surface due to the absorption of 
biological compounds on the enzymatic membrane. In this perspective, the slow flow rate could represent a disadvantage since it will not be able to rapidly remove these compounds from the volume surrounding the electrode. An inhibition of the enzyme by certain compounds present in the subcutaneous tissue could also lead to an underestimation of the glucose present in the blood.

For this reason, experiments to test the operational stability of glucose sensors have been performed with dialysed biological samples. Microdialysis probes were inserted into a biological solution (i.e. human serum with glucose and a preservative added) and the signal due to glucose was continuously monitored for ca. $24 \mathrm{~h}$. A control solution of glucose $\left(5 \mathrm{mmoll}^{-1}\right)$ was also used to estimate the stability of the sensors. From the results shown in Fig. 24.4, it seems that the presence of biological compounds in the solution does not contribute to a lower stability of the probe since the signal due to the control solution of glucose is almost unchanged after ca. $20 \mathrm{~h}$. This is an important result because even in the absence of any cut-off membrane placed on the

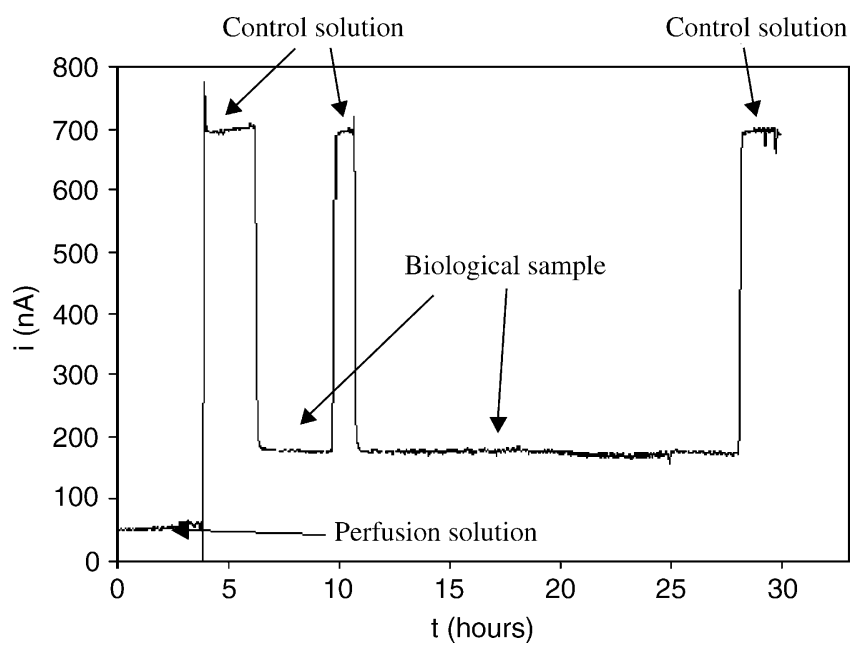

Fig. 24.4. Study of the biosensor stability with biological sample. Arrows indicate where (i.e. biological sample) a solution obtained by dialysing a human serum with the microdialysis probe was flowed in the biosensor cell. At the beginning a perfusion solution and control solution (glucose $5 \mathrm{mmoll}^{-1}$ ) were used instead of the serum to test the biosensor response. Control solution of glucose was also used during and at the end of the experiment to evaluate the stability of the biosensor. Continuous flow mode: $10 \mu \mathrm{min}^{-1}$ ). Applied potential: $-50 \mathrm{mV}$ vs. int. ref. Reprinted from Ref. [59] with permission from Elsevier. 
electrode surface, a high stability could be achieved in the presence of complex fluids.

\subsubsection{Storage stability of glucose biosensors}

To evaluate the shelf life of the glucose biosensors, a series of sensors were produced and stored at RT (i.e. $25^{\circ} \mathrm{C}$ and dry) and at $45^{\circ} \mathrm{C}$ in an oven (dry). Three biosensors were then tested for glucose $\left(0.5 \mathrm{mmoll}^{-1}\right)$ response to determine their residual activity. Taking into account the good reproducibility of these biosensors (ca. 7\%) it is possible to evaluate the residual activity by looking only at the signal of the electrodes after the study of each storage interval and reporting, as reference signal for the initial activity, an average value obtained with six new biosensors. The results are shown in Fig. 24.5. As can be seen, the storage stability of these biosensors is extremely good and can be ascribed to the well-known stability of the glucose oxidase enzyme. These results also confirm the high stability of the PB layer during storage. Moreover, looking at the results obtained at $45^{\circ} \mathrm{C}$ (an average decrease response of ca. $10 \%$ after 60 days), it could be concluded that the shelf life of these biosensors is another encouraging point relative to their use in continuous glucose monitoring.

\subsubsection{Acetylcholinesterase biosensors}

The measurement of thiocholine discussed in Section 24.2.1.4 was used for the detection of pesticides by the study of the residual activity of
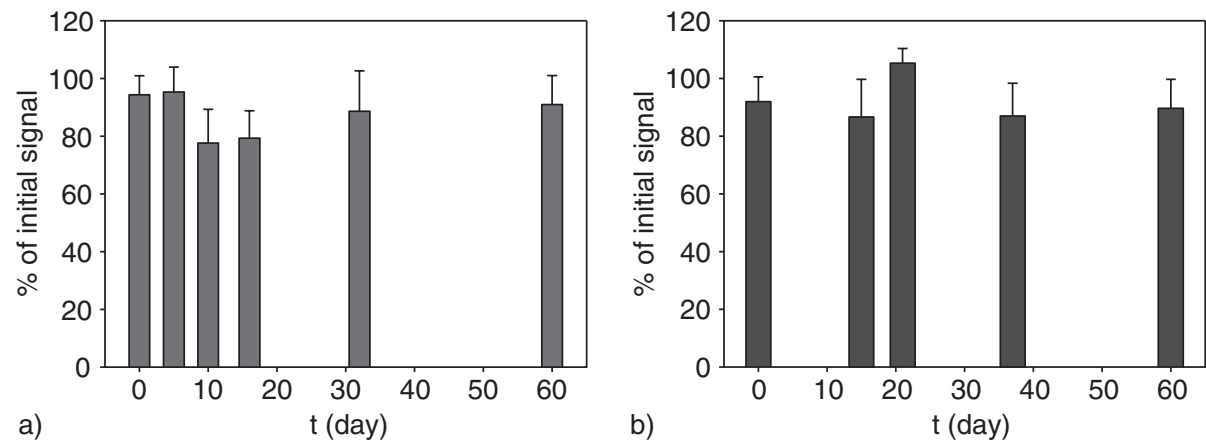

Fig. 24.5. Storage stability studies. Percentage of initial activity of different glucose biosensors after the storage time. (a) Biosensors stored at RT (i.e. $25^{\circ} \mathrm{C}$ and dry). (b) Biosensors stored at $45^{\circ} \mathrm{C}$ (dry). For each period, three biosensors were tested. See text for details. Reprinted from Ref. [59] with permission from Elsevier. 
acetylcholinesterase [55] according to the following reaction:

Acetylthiocholine $\stackrel{\mathrm{H}_{2} \mathrm{O}, \mathrm{AChE}}{\longrightarrow}$ Thiocholine + Acetic Ac.

Acetylcholinesterase (AChE, from electric eel) was immobilised on the PB-modified screen-printed electrode and inhibition measurements were first carried out using standard solutions of an organophosphorous (i.e. Paraoxon) and a carbammic (i.e. Aldicarb) pesticide.

The inhibition and the subsequent signal detection were performed in two different solutions. First the pesticide solution was added and then after $10 \mathrm{~min}$ (incubation time) the sensor was moved into a new buffer solution where the substrate $\left(5 \mathrm{mmoll}^{-1}\right.$ acetylthiocholine) was injected and the signal measured. This procedure is particularly suitable when a complex matrix, which could pose problems for the direct measurement of thiocholine oxidation, is used. The analytical characteristics of pesticide determination in standard solutions were then evaluated. Detection limits, defined in this work as the concentrations giving an inhibition of $20 \%$, were 30 and $10 \mathrm{ppb}$ for aldicarb and paraoxon, respectively. By increasing the incubation time up to $30 \mathrm{~min}$, an increase in the degree of inhibition could be observed and lower detection limits both for Aldicarb (5ppb) and Paraoxon (3ppb) were achieved.

$\mathrm{ChE} / \mathrm{PB}$ sensors showed a high reproducibility resulting in a relative standard deviation for the pesticide determination of $7 \%(n=5)$. The results were obtained with single-use $\mathrm{ChE} / \mathrm{PB}$ sensors.

These sensors have then been adopted for the quantification of pesticides in grape samples. Anticholinesterase pesticides are in fact widely used in the production of table and wine grapes [56]. The maximum permissible levels of pesticides in wine grapes during harvesting are $0.1-0.5 \mathrm{mg} \mathrm{kg}^{-1}$. Although more than $80 \%$ of pesticides decompose during grape fermentation, the influence of pesticides on fermentation and wine quality is a matter of concern. Anticholinesterase pesticides are spontaneously hydrolysed in the environment to their non-toxic products. However, the rate of this process is strongly affected by matrix characteristics. For this reason, a study of the fate of two standard pesticides during wine fermentation was carried out.

Either Aldicarb or Paraoxon was added to grape juice at the beginning of grape fermentation.

The amount of pesticide was evaluated during the initial days of fermentation. The sensor was incubated for $10 \mathrm{~min}$ with must, then washed and immersed into the standard buffer solution for signal 
F. Ricci, D. Moscone and G. Palleschi

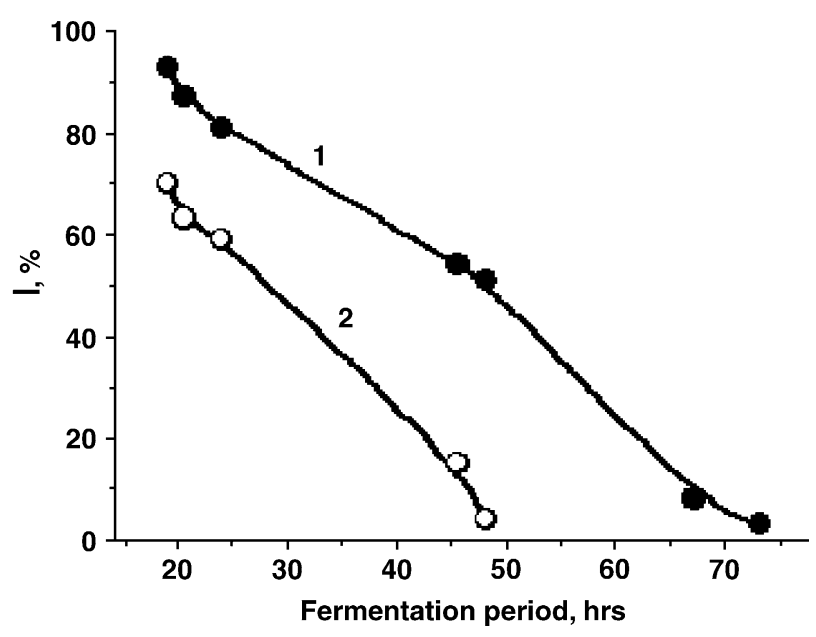

Fig. 24.6. The degree of inhibition measured in fermentation process of white grape juice spiked with (1) $500 \mathrm{ppb}$ of Paraoxon and (2) $500 \mathrm{ppb}$ of Aldicarb. Reprinted from Ref. [55] with kind permission of Springer Science.

measurement. Blank and spiked samples of juice under fermentation were tested without any treatment step. The results of the monitoring of pesticide degradation are shown in Fig. 24.6. The Paraoxon and Aldicarb life-time was estimated as 3 and 2 days, respectively. The decrease of the inhibition during the fermentation can be also due to interaction of pesticides with matrix components; in any case, this trend corresponds to the reported HPLC estimation of pesticide residues in wine and in fermentation media [56-58]. In accordance with their results, we found that about $90 \%$ of initial amounts of pesticides tested decomposed during the first 3 days of fermentation.

\subsection{CONCLUSIONS}

The need for electrochemical sensors which are able to monitor important analytes at low concentrations and with little or low interference effect and which could also allow mass production of probes and an in situ application has become more and more urgent during recent years.

The modified sensors for $\mathrm{H}_{2} \mathrm{O}_{2}$ and thiocholine detection presented in this chapter seem to be an adequate response to this demand. The use of PB-modified sensors has in fact been demonstrated to be extremely useful for $\mathrm{H}_{2} \mathrm{O}_{2}$ amperometric detection at low applied 
potentials with a number of possible biosensor applications based on oxidase enzymes. Moreover, the demonstration of the electrocatalytic effect of $\mathrm{PB}$ towards thiocholine oxidation represents an important finding for the construction of acetylcholinesterase biosensors for pesticide detection.

Finally, the optimisation of a procedure suitable for the deposition of a PB layer on a large number of screen-printed electrodes in a timeeffective way makes the use of the sensors presented in this chapter particularly advantageous.

The analytical parameters of the PB-modified sensors towards $\mathrm{H}_{2} \mathrm{O}_{2}$ and thiocholine were carefully evaluated at an applied potential of -50 and $+200 \mathrm{mV}$ vs. $\mathrm{Ag} / \mathrm{AgCl}$, respectively. A detection limit of $10^{-7}$ and $10^{-6} \mathrm{moll}^{-1}$ was obtained for $\mathrm{H}_{2} \mathrm{O}_{2}$ using a stirred batch amperometry and a continuous flow mode, respectively. In both cases, the level of electrochemical interference was very low and equal to $2 \%$ for ascorbic acid, while no detectable signals were observed for uric acid and catechol $\left(0.05 \mathrm{moll}^{-1}\right)$. In the case of thiocholine, a lower signal was observed with a detection limit of $5.0 \times 10^{-6} \mathrm{moll}^{-1}$. PB-modified sensors have also demonstrated a very high operative stability even at alkaline $\mathrm{pH}$, which makes possible the use of these probes in continuous mode for up to $50 \mathrm{~h}$ at $\mathrm{pH} 7.4$ and for $20 \mathrm{~h}$ at $\mathrm{pH} 9.0$.

Two applications of the PB-modified screen-printed electrodes were reported. The first one is based on the coupling of the modified sensor with glucose oxidase for assembling a glucose biosensor to be applied in a continuous glucose monitoring. Analytical parameters such as stability of the biosensor were found to be satisfactory. The operational stability was found to be suitable for clinical application. Moreover, studies with biological samples demonstrated that the biosensor signal was not affected by the presence of interferents. Storage stability was found to be very high, with a loss of activity of only $10 \%$ after 2 months and at $45^{\circ} \mathrm{C}$ under dry conditions, and no loss after 1 year of storage at room temperature.

In the second application, the use of PB-modified sensors as powerful tools for thiocholine detection has been proposed for pesticide quantification in grape samples during wine fermentation. Two standard pesticides were used, one belonging to the class of carbamates (aldicarb) and another to the class of organophosphates (paraoxon). In both cases, the detection limits were found to be in the ppb range. The detection of anticholinesterase pesticides was demonstrated to be accurate even in a complicated matrix such as grape juice during fermentation. The limits of detection are low enough to detect the trace amounts of 
pesticides at the level of their admissible concentrations in wine grapes or soil. Taking into account the accuracy of the probe signal and the variation of the matrix content, $\mathrm{ChE} / \mathrm{PB}$ sensors can be used for semiquantitative estimation of pesticide traces in grapes and must and for preliminary tests of contaminant levels in the field.

\section{REFERENCES}

1 L. Gorton, Chemically modified electrodes for the electrocatalytic oxidation of nicotinamide coenzymes, J. Chem. Soc., Faraday Trans, 82 (1986) 1245-1258.

2 P.N. Bartlett, P. Tebbutt and R.P. Whitaker, Kinetic aspects of the use of modified electrodes and mediators in bioelectrochemistry, Progr. React. Kinet., 16 (1991) 55-156.

3 F.D. Munteanu, D. Dicu, I.C. Popescu and L. Gorton, NADH oxidation using carbonaceous electrodes modified with dibenzo-dithiadiazapentacene, Electroanalysis, 15 (2003) 383-391.

4 C.O. Schmakel, K.S.V. Santhanam and P.J. Elving, Nicotinamide adenine dinucleotide $(\mathrm{NAD}+)$ and related compounds. Electrochemical redox pattern and allied chemical behavior, J. Am. Chem. Soc., 97(18) (1975) 5083-5092.

5 J. Moiroux and P.J. Elving, Adsorption phenomena in the NAD+/NADH system at glassy carbon electrodes, J. Electroanal. Chem., 102 (1979) 93-108.

6 S. Andreescu, L. Barthelmebs and J.-L. Marty, Immobilization of acetylcholinesterase on screen-printed electrodes: comparative study between three immobilization methods and applications to the detection of organophosphorus insecticides, Anal. Chim. Acta, 464(2) (2002) $171-180$.

7 G. Jeanty and J.L. Marty, Detection of paraoxon by continuous flow system based enzyme sensor, Biosens. Bioelectron., 13(2) (1998) 213-218.

8 L. Doretti, D. Ferrara, S. Lora, F. Schiavon and F.M. Veronese, Acetylcholine biosensor involving entrapment of acetylcholinesterase and poly(ethylene glycol)-modified choline oxidase in a poly(vinyl alcohol) cryogel membrane, Enzyme Microb. Technol., 27 (2000) 279-285.

9 F. Ricci, F. Arduini, A. Amine, D. Moscone and G. Palleschi, Characterisation of Prussian blue modified screen-printed electrodes for thiol detection, J. Electroanal. Chem., 563 (2004) 229-237.

10 J.-L. Marty, N. Mionetto, T. Noguer, F. Ortega and C. Roux, Enzyme sensors for the detection of pesticides, Biosens. Bioelectron., 8 (1993) 273-280.

11 J.L. Marty, N. Mionetto, S. Lacorte and D. Barcelo, Validation of an enzymic biosensor with various liquid-chromatographic techniques for 
determining organophosphorus pesticides and carbaryl in freeze-dried waters, Anal. Chim. Acta, 311 (1995) 265-271.

12 G. Palleschi, M.A. Nabi Rahni, G.J. Lubrano, J.N. Nwainbi and G.G. Guilbault, A study of interferences in glucose measurements in blood by hydrogen peroxide based glucose probes, Anal. Biochem., 159 (1986) 114-121.

13 L. Gorton, Carbon paste electrodes modified with enzymes, tissues, and cells, Electroanalysis, 7 (1995) 23-45.

14 A. Lindgren, T. Ruzgas, L. Gorton, E. Csoregi, G. Bautista Ardila, I.Y. Sakharov and I.G. Gazaryan, Biosensors based on novel peroxidases with improved properties in direct and mediated electron transfer, Biosens. Bioelectron., 15 (2000) 491-497.

15 S. Razola Serradilla, B. Ruiz Lopez, N. Diez Mora, H.B. Mark and J.M. Kauffmann, Hydrogen peroxide sensitive amperometric biosensor based on horseradish peroxidase entrapped in a polypyrrole electrode, Biosens. Bioelectron., 17(11-12) (2002) 921-928.

16 E. Csoregi, L. Gorton, G. Marko-Varga, A.J. Tudos and W.T. Kok, Peroxidase-modified carbon fiber microelectrodes in flow-through detection of hydrogen peroxide and organic peroxides, Anal. Chem., 66 (1994) 3604.

17 T. Ruzgas, E. Csoregi, J. Emmeus, L. Gorton and G. Marko-Varga, Peroxidase-modified electrodes: fundamentals and application, Anal. Chim. Acta, 220 (1996) 123-138.

18 J.D. Newman, S.F. White, I.E. Tothill and A.P.F. Turner, Catalytic materials, membranes, and fabrication technologies suitable for the construction of amperometric biosensors, Anal. Chem., 67 (1995) 4594-4607.

19 A. Chaubey and B.D. Malhorta, Mediated Biosensors, Biosens. Bioelectron., 17 (2002) 441-456.

20 J.M. Zen, A.S. Kumar and D.M. Tsai, Recent updates of chemically modified electrodes in analytical chemistry, Electroanalysis, 15(13) (2003) 1073-1087.

21 A.A. Karyakin, Prussian blue and its analogues: electrochemistry and analytical applications, Electroanalysis, 13 (2001) 813-819.

22 R. Koncki, Chemical sensors and biosensors based on Prussian blues, Crit. Rev. Anal. Chem., 32(1) (2002) 79-96.

23 F. Ricci and G. Palleschi, Sensor and biosensor preparation, optimisation and applications of Prussian Blue modified electrodes, Biosens. Bioelectron., 21 (2005) 389-407.

24 A.A. Karyakin, O. Gitelmacher and E.E. Karyakina, A high-sensitive glucose amperometric biosensor based on Prussian blue modified electrodes, Anal. Lett., 27(15) (1994) 2861-2869.

25 A.A. Karyakin, O.V. Gitelmacher and E.E. Karyakina, Prussian bluebased first-generation biosensor. A sensitive amperometric electrode for glucose, Anal. Chem., 67 (1995) 2419-2423. 
26 A.A. Karyakin, E.E. Karyakina and L. Gorton, Prussian-blue based amperometric biosensors in flow-injection analysis, Talanta, 43 (1996) $1597-1606$.

27 B.B. Hasinoff and H.B. Dunford, Kinetics of the oxidation of ferrocyanide by horseradish peroxidase compounds I and II, Biochemistry, 9 (1970) 4930-4932.

28 K. Itaya, N. Shoji and I. Uchida, Catalysis of the reduction of molecular oxygen to water at Prussian blue modified electrodes, J. Am. Chem. Soc., 106 (1984) 3423-3429.

29 A.A. Karyakin, E.E. Karyakina and L. Gorton, The electrocatalytic activity of Prussian blue in hydrogen peroxide reduction studied using a wall-jet cell with continuous flow, J. Electroanal. Chem., 456 (1998) 97-104.

30 Q. Chi and S. Dong, Amperometric biosensors based on the immobilization of oxidases in a Prussian blue film by electrochemical codeposition, Anal. Chim. Acta, 310 (1995) 429-436.

31 S.A. Jaffari and A.P.F. Turner, Novel hexacyanoferrate (III) modified graphite disc electrodes and their application in enzyme electrodes (Part I), Biosens. Bioelectron., 12 (1997) 1-9.

32 Q. Deng, B. Li and S. Dong, Self-gelatinizable copolymer immobilized glucose biosensor based on Prussian blue modified graphite electrode, Analyst, 123 (1998) 1995-1999.

33 R. Garjonyte and A. Malinauskas, Electrocatalytic reactions of hydrogen peroxide at carbon paste electrodes modified by some metal hexacyanoferrates, Sens. Actuators B, 46 (1998) 236-241.

34 K. Itaya, H. Akahoshi and S. Toshima, Electrochemistry of Prussian blue modified electrodes: an electrochemical preparation method, J. Electrochem. Soc., 129(7) (1982) 1498-1500.

35 R. Garjonyte and A. Malinauskas, Amperometric glucose biosensors based on Prussian blue and polyaniline glucose oxidase modified electrodes, Biosens. Bioelectron., 15 (2000) 445-451.

36 R. Garjonyte, Y. Yigzaw, R. Meskys, A. Malinauskas and L. Gorton, Prussian-blue and lactate oxidase-based amperometric biosensor for lactic acid, Sens. Actuators B, 79 (2001) 33-38.

37 A.A. Karyakin, E.E. Karyakina and L. Gorton, Amperometric biosensor for glutamate using Prussian blue-based 'artificial peroxidase' as a transducer for hydrogen peroxide, Anal. Chem., 72 (2000) $1720-1723$.

38 N.R. de Tacconi, K. Rajeshwar and R.O. Lezna, Metal hexacyanoferrate: electrosynthesis, in situ characterization and applications, Chem. Mater., 15 (2003) 3046-3062.

39 J.P. Hart and S.A. Wring, Recent developments in the design and application of screen-printed electrochemical sensors for biomedical, environmental and industrial analyses, TRAC, 16 (1997) 89-103. 
40 M. Albareda-Silvert, A. Merkoci and S. Alegret, Configurations used in the design of screen printed enzymatic biosensors. A review, Sens. Actuators B, 69 (2000) 153-163.

41 J.P. Hart, A. Crew, E. Crouch, K. Honeychurch and R. Pemberton, Some recent design and developments of screen-printed carbon electrochemical sensors/biosensors for biomedical, environmental and industrial analyses, Anal. Lett., 37(5) (2004) 789-830.

42 R. Garjonyte and A. Malinauskas, Operational stability of amperometric hydrogen peroxide sensors, based on ferrous and copper hexacyanoferrates, Sens. Actuators B, 56 (1999) 93-97.

43 R. Garjonyte and A. Malinauskas, Glucose biosensor based on glucose oxidase immobilized in electropolymerized polypyrrole and poly(o-phenylenediammine) films on a Prussian blue-modified electrode, Sens. Actuators B, 63 (2000) 122-128.

44 X. Zhang, J. Wang, B. Ogorevc and U.S. Spichiger, Glucose nanosensor based on Prussian-blue modified carbon-fiber cone nanoelectrode and an integrated reference electrode, Electroanalysis, 11 (1999) 945-949.

45 B.J. Feldman and R.W. Murray, Electron diffusion in wet and dry Prussian blue films on interdigitated array electrodes, Inorg. Chem., 26 (1987) 1702-1708.

46 A.A. Karyakin, E.E. Karyakina and L. Gorton, On the mechanism of $\mathrm{H}_{2} \mathrm{O}_{2}$ reduction at Prussian Blue modified electrodes, Electrochem. Commun., 1 (1999) 78-82.

47 A. Malinauskas, R. Araminaite, G. Mickeviciute and R. Garjonyte, Evaluation of operational stability of Prussian blue and cobalt hexacyanoferrate-based amperometric hydrogen peroxide sensors for biosensing application, Mater. Sci. Eng. C, 24 (2004) 513-519.

48 D. Moscone, D. D'Ottavi, D. Compagnone, G. Palleschi and A. Amine, Construction and analytical characterization of Prussian blue based carbon paste electrodes and their assembly as oxidase enzyme sensors, Anal. Chem., 73 (2001) 2529-2535.

49 F. Ricci, A. Amine, G. Palleschi and D. Moscone, Prussian blue based screen printed biosensors with improved characteristics of long-term lifetime and pH stability, Biosens. Bioelectron., 18 (2003) 165-174.

50 F. Ricci, A. Amine, C.S. Tuta, A.A. Ciucu, F. Lucarelli, G. Palleschi and D. Moscone, Prussian blue and enzyme bulk modified screen-printed electrodes for hydrogen peroxide and glucose determination with improved storage and operational stability, Anal. Chim. Acta, 485 (2003) 111-120.

51 D. Moscone and M. Mascini, Microdialysis coupled with glucose biosensor for subcutaneous monitoring, Analysis, 21 (1993) M40-M42.

52 C. Meyeroff, F. Bischof, F. Sternberg, H. Zier and E.F. Pfeiffer, On line continuous monitoring of subcutaneous tissue glucose in men by combining portable glucose sensor with microdialysis, Diabetologia, 35 (1992) 224-230. 
F. Ricci, D. Moscone and G. Palleschi

53 D. Moscone, M. Pasini and M. Mascini, Subcutaneous microdialysis probe coupled with glucose biosensor for in vivo continuous monitoring, Talanta, 39(8) (1992) 1039-1044.

54 D. Moscone and M. Mascini, Microdialysis and glucose biosensor for in vivo monitoring, Ann. Biol. Clin., 21 (1993) M40-M42.

55 E. Suprun, G. Evtugyn, H. Budnikov, F. Ricci, D. Moscone and G. Palleschi, Acetylcholinesterase sensor based on screen-printed carbon electrode modified with Prussian blue, Anal. Bioanal. Chem., 383 (2005) 597-604.

56 FAO, Submission and Evaluation of Pesticide Residues Data for the Estimation of Maximum Residue Levels in Food and Feed, 1st ed., FAO, Rome, 2002.

57 J.R. Corbett, The Biochemical Mode of Action of Pesticides, Academic Press, London, 1974.

58 P. Cabras and A. Angioni, Pesticide residues in grapes, wine, and their processing products, J. Agric. Food Chem., 48 (2000) 967-973.

59 F. Ricci, D. Moscone, C.S. Tuta, G. Palleschi, A. Amine, A. Poscia, F. Valgimigli and D. Messeri, Novel planar glucose biosensors for continuous monitoring use, Biosens. Bioelectron., 20(10) (2005) 1993-2000. 